\begin{tabular}{lllllllllllllllllllllllllllllllll}
\hline$R$ & $E$ & $V$ & I & S & T & A & D & E & E & S & T & U & D & I & O & S & I & N & T & E & R & N & A & C & I & O & N & A & L & E & S
\end{tabular}

\title{
Chile, Nueva Zelandia y Singapur: socios del nuevo mundo en el Pacífico
}

\author{
Sergio Valdivieso
}

\begin{abstract}
El presente artículo analiza en profundidad y con foco de futuro el contexto dinámico, las relaciones, alcances e impactos de la estrategia diseñada por estos socios del nuevo mundo -denominado Acuerdo de Asociación Económica-Pacífico Tres a formalizarse durante 2005- para enfrentar conjuntamente los desafios que presenta la globalización a pequeños países democráticos con economías abiertas y competitivas. Especialmente en cuanto a la promoción, defensa y accionar respecto de sus visiones e intereses comunes en los múltiples ámbitos del Pacífico y en su esfuerzo por potenciar y capitalizar sus ventajas que les permitan acrecentar el desarrollo y el bienestar de sus poblaciones.
\end{abstract}

\section{BASES Y ACCIÓN INTERNACIONAL DE SINGAPUR}

ingapur atestiguó en el siglo veinte la declinación colonial británica en la región de Asia-Pacífico, detentó la condición de Estado autodeterminado miembro de la federación de Malasia y se transformó finalmente en república independiente. Este pequeño país-isla del Sudeste asiático es un ejemplo notable de país dinámico que alcanzó el desarrollo y la prosperidad, escalando del llamado tercer mundo al primer mundo, por medio de un rápido y sostenido crecimiento económico basado en su integración al exterior, el desarrollo del área de los servicios, la aplicación de tecnologías y la agregación de valor a los procesos de negocios, la capacitación de sus recursos humanos y una importante cohesión social.

En materia de política exterior, su visión del mundo, de la región de Asia Pacífico y de cómo actuar en esta, conjugando intereses nacionales y globales, ha ejercido importante influencia en la región. Bajo la dirección de Lee Kwan Yew, su líder entre 1959 y 1990 y hasta la fecha, 
el libre comercio e inversión y las alianzas globales entre las naciones de la región de Asia Pacífico han sido factores supremos del éxito. A largo plazo, interesa a Singapur promover y concretar acuerdos con otras naciones de APEC, de modo de avanzar en la liberalización comercial y por esa vía aumentar el desarrollo y el bienestar de su población.

\section{Consideraciones económicas y estratégicas actuales}

En la actualidad, el accionar internacional de Singapur se ve influido por consideraciones económicas y estratégicas respecto del futuro de la región de Asia Pacífico, entre las que cabe destacar que:

- China es ya un actor formidable en la región, previéndose que ninguna combinación de otras economías del este asiático -Japón, Corea del Sur, Taiwán y la Asociación de Naciones del sudeste asiático- podrá equiparar su poder.

- Para el año 2040, el PGB combinado de China y Japón excederá al de los Estados Unidos y el eje de gravitación en el mundo económico tendrá su centro indiscutidamente en el Pacífico;

- La agresiva liberalización y desregulación experimentada por el noreste asiático ha desdibujado la diferencia antes existente entre el noreste y el sudeste asiático, teniendo como resultado un crecimiento sustantivo y un mayor dinamismo en las inversiones extranjeras directas y los flujos de capital hacia el noreste;

- En el sudeste, por su parte, Indonesia no logra establecer un orden que genere confianza a la inversión extranjera y;

- Las actuales visiones estratégicas del futuro, la ausencia de conflicto en temas económicos y el conocimiento y confianza alcanzados por países como Singapur, Australia y Nueva Zelandia, contribuyen a una convergencia importante en la región, aun cuando no hay una visión común en el sudeste respecto de los principales países de Oceanía, lo que posterga el sueño de algunos de tener un área de libre comercio asiática suroriental de gran escala que los incluya.

\section{Alianzas regionales}

El crecimiento de China plantea a las naciones de Asia sudoriental la necesidad de completar sus esfuerzos en pos de crear áreas de libre comercio que les permitan alcanzar el desafío económico de ser atractivos a la inversión extranjera china. Para tener prosperidad económica, los países de la Asociación de Naciones del Sureste Asiático, que ya suscribieron un acuerdo económico con China, deben combinar sus mercados en un área de libre comercio de ASEAN, con ese propósito.

\section{El libre comercio, la inversión y las alianzas globales con naciones de Asia- Pacífico han sido factores importantes del éxito de Singapur.}

Una forma de interactuar con eficacia en este contexto podría darse establecien- 
do un nuevo grupo regional del norte y del sur de los países asiáticos del este, dentro del marco de APEC. Dado el retraso en el desarrollo de los acuerdos de libre comercio en el contexto de AFTA-CER (Área de Libre Comercio de ASEAN con Australia y Nueva Zelandia), este grupo podría renovar los esfuerzos de libre comercio a través de la región y proporcionar nuevos espacios para abordar la ampliación de los miembros de APEC, a los cuales se incorporaron en años pasados la Federación de Rusia, Chile y Perú.

\section{El crecimiento de China obliga a las}

naciones de Asia sudoriental a crear áreas de libre comercio que les permitan atraer la inversión extranjera china.

Se ha considerado generar dentro de APEC un subgrupo de asiáticos del este y de australasios, equivalente al subgrupo del este del Pacífico, integrado por los Estados Unidos, Canadá y México en NAFTA. En ese contexto, se visualizó "ASEAN más tres en Asia del este del norte, más dos en Australasia”. Ese grupo podría avanzar mejor en relación con los intereses comunes del lado occidental del Pacífico en la liberalización comercial y en resistir cualquier resurgimiento del proteccionismo. Desde el punto de vista de Lee Kwan Yew -2000-, la presencia de Australia y Nueva Zelandia en un grupo subregional podrían traer a los Estados Unidos en torno al libre comercio a la región asiática, "más por la persuasión que por argumentos".
Aún falta para concretar los acuerdos de AFTA-CER respecto de la iniciativa emprendida en 1995 por los ministros del área económica de la ASEAN y los ministros de Australia y de Nueva Zelandia (países del CER) para facilitar los flujos del comercio e inversión entre ambas regiones. Si bien persiste la visión de avanzar hacia una integración económica mayor mediante un acuerdo comercial regional entre los países representados en ambas organizaciones, las posiciones disímiles, en cuanto al desarrollo de la industria y la estabilidad financiera al interior de las diez naciones de la ASEAN han hecho que las expectativas recientes de suscribir un acuerdo de libre comercio sean difíciles de alcanzar.

\section{Acuerdos y asociaciones bilaterales}

Los principales avances en las relaciones de los países de Australasia con los de ASEAN se están dando en materia de acuerdos bilaterales. Si bien a nivel de grupo las relaciones se han desenvuelto con menor celeridad que la deseada, Singapur, Nueva Zelandia y Australia han avanzado en potenciar sus relaciones bilaterales y consolidar su posición con los países asiáticos que comparten su visión del mundo.

Singapur, al igual que otros países miembros de APEC, considera que la ruta ideal al libre comercio es a través del multilateralismo. Sin embargo, ve en las asociaciones de dos o más países que aumentan los espacios al libre comercio una oportunidad para contribuir a que los países de APEC continúen moviéndose 
hacia las metas de Bogor. Su actual Primer Ministro, Goh Chok Tong, ha indicado que "aquellos países que deseen expandirse por medio de Acuerdos de Libre Comercio deben hacerlo y andar más rápido que aquellos que no quieran correr" y esta es parte importante de la actual estrategia de Singapur, que considera que los nuevos acuerdos -inicialmente bilaterales- serán el camino más expedito para avanzar hacia el libre comercio, posibilitando nuevos acuerdos trilaterales y regionales.

\section{La ruta ideal al libre comercio es a través del multilateralismo.}

En la presente década y bajo esa visión, Singapur inició negociaciones bilaterales con países de APEC, tales como los Estados Unidos, Nueva Zelandia, Australia, Japón, México y Chile. En estas negociaciones ha alcanzado éxito con Nueva Zelandia, país con el que suscribió un Pacto de Asociación Económica, y con los Estados Unidos, país con el que en 2003 suscribió un Tratado de Libre Comercio. Los planes en curso incluyen incorporar a Chile al acuerdo con Nueva Zelandia-Pacífico 3- y pactar acuerdos bilaterales adicionales con Canadá y Corea del Sur.

Con Estados Unidos, Singapur mantiene una sólida y estrecha relación transpacífica, basada en intereses económicos y estratégicos comunes, tales como la lucha contra el terrorismo, sus vínculos en el sector de la defensa, su compromiso con el libre comercio y la inver- sión extranjera y el sistema multilateral de comercio. En las últimas tres décadas, Estados Unidos ha colaborado estrechamente con ASEAN en temas de seguridad, ha abierto sus mercados, compartido tecnologías e invertido capital en esas economías, en tiempos y áreas cruciales para el desarrollo de las mismas. Consciente de que el intercambio de bienes, servicios, inversiones, personas, ideas y tecnologías con Estados Unidos ha contribuido a su expansión, luego de negociaciones iniciadas en la reunión de APEC en Brunei, Singapur suscribió un acuerdo de libre comercio con Estados Unidos, que aportará bases requeridas para potenciar los crecientes vínculos económicos.

Este acuerdo, que servirá de marco para otros con países de ASEAN, es una poderosa señal de compromiso de largo plazo de los Estados Unidos con Singapur, el sudeste asiático y su desarrollo. Es ambicioso e integral al remover barreras en el comercio de bienes y servicios y, la inversión y plantear reglas y estándares en materias tales como el $e$ commerce, la propiedad intelectual y la transparencia.

Australia, país con el que Singapur ha tenido estrechas relaciones, flexibilizó su posición respecto de negociar acuerdos bilaterales de libre comercio, luego de acordarse el Pacto de Asociación Económica entre Nueva Zelandia y Singapur. Este facilitó la negociación de un acuerdo con Singapur, constituyendo la segunda experiencia de este tipo para el mayor país Oceánico, luego de su pacto en 1983 con Nueva Zelandia. 
VISIÓN Y ACCIÓN INTERNACIONAL De Nueva Zelandia

Nueva Zelandia es un país insular, poco poblado, con un territorio equivalente al de Japón y que mantiene fuertes vínculos con Gran Bretaña. Su población y cultura dominante son mayoritariamente de origen anglosajón y por años su economía se estructuró para proveer de materias primas -principalmente agrícolas-a Inglaterra, a la vez de destacar su relación estrecha con Australia, su más cercano vecino en el Pacífico. Nueva Zelandia es país miembro de la OCDE, entre cuyos asociados figuran otras ex colonias de Inglaterra, de mayor bienestar económico, tales como Australia, Canadá y Estados Unidos.

En la década de los ochenta, Nueva Zelandia debió mirar a la populosa región asiática, asignándole mayor valor, mientras debía repensar su estrategia económica para salir a competir al mundo. Las causas pueden resumirse en la significativa dependencia de sólo dos países que hasta entonces presentaba su economía. Gran Bretaña, que debió orientarse a la Comunidad Europea, terminando con los privilegios para la entrada de alimentos de la "Commonwealth" y Australia, su más cercano vecino -1.800 kilómetros al sureste- que debió potenciar entonces su relación con Estados Unidos.

\section{Opciones de alianzas para}

Nueva Zelandia en el siglo XXI

En 1998 y con referencia a su localización geográfica, su actual Primera Mi- nistra, Helen Clark, vislumbraba a Nueva Zelandia actuando como puente entre países de dos hemisferios diferentes $y$ crecientemente integrados en el mundo global. En el trasfondo de este planteamiento está la aspiración neozelandesa de ampliar sus alianzas en el contexto internacional, más allá de aquélla histórica con las naciones occidentales de habla inglesa y la opción real de aliarse a vecinos asiáticos, de notable desempeño económico y creciente influencia internacional.

\section{El acuerdo entre Singapur y los Estados Unidos establece reglas y estándares en materias tales como el e-commerce, la propiedad intelectual y la transparencia.}

Durante más de 30 años, Nueva Zelandia ha diversificado sus relaciones y, desde esta perspectiva, forjar vínculos amplios con los vecinos del Asia-Pacífico es visto como una opción de futuro respecto de sus anteriores alianzas, limitadas a un reducido número de naciones de origen común. La posición en que están Nueva Zelandia y Australia respecto de Asia en el Pacífico es privilegiada, por lo que asigna a ese continente una muy alta prioridad, a la vez que su base común europeo-occidental le permite seguir cultivando sus relaciones con Europa, América del Norte y las naciones del Commonwealth, y contribuyen a unir estos dos mundos. Esto constituye un activo para la construcción y la potenciación de vínculos y relaciones. 
APEC es vista por Nueva Zelandia como una instancia que une este y oeste, reuniendo a China y Estados Unidos en torno a objetivos e intereses comunes. La visión neozelandesa es la de trabajar y aportar juntos en estas instancias regionales por un futuro común, a lo que ha contribuido con propuestas y agendas concretas. Importante prioridad ocupan también su participación en el proceso de AFTA-CER para mejorar su perfil en estos mercados y el Acuerdo de Asociación Económica suscrito con Singapur y sus negociaciones con China y Hong Kong, Malasia y Tailandia.

Hasta hace poco, prestó escasa atención a los mercados latinoamericanos, lo que cambió con posterioridad a su presidencia de APEC. En agosto de 2000, el gobierno neozelandés lanzó su "Estrategia Latinoamericana", un programa para ampliar y potenciar contactos y vínculos económicos, comerciales, políticos, culturales y a nivel de las comunidades. América Latina presenta un potencial para Nueva Zelanda. Se estima que hacia 2015 la población del continente alcanzará a 625 millones. En 2000 su PIB fue de 1.945 millones de dólares, y se espera que aumente, en la medida en que sus países resuelvan conflictos internos, mejoren sus estructuras democráticas y profundicen reformas económicas que les provean la base para el crecimiento sustentable y el aumento del tamaño del mercado consumidor latinoamericano.

\section{La política exterior neozelandesa}

Definiciones fundamentales de la política exterior neozelandesa son que debe ser multi-dimensional y proyectar al país al mundo en forma amplia. Debido a su aislamiento geográfico, Nueva Zelandia -como Chile y Singapur- mira en forma activa más allá de sus costas, respaldando sus propias ideas, metas e intereses. Para comprenderla se requiere analizar los principios y fuerzas institucionales que tradicionalmente han actuado sobre ésta. Desde 1930, la idea de independencia ha estado fuertemente presente, no en un sentido secesionista o revolucionario, sino de independencia de intereses, vista como una forma de disensión, de crítica progresista a un patrón existente, sin desafiar su estructura subyacente. Este componente de independencia ha estado presente en la política exterior de los dos partidos políticos que han detentado el poder desde entonces, no obstante éstos se alinean en diferentes escuelas de pensamiento en materia de relaciones internacionales. El laborismo ha seguido de cerca el paradigma liberal internacionalista, mientras que el Partido Nacional presenta algunas coincidencias con el modelo realista.

\section{Se vislumbraba a Nueva Zelandia como puente entre países de dos hemisferios diferentes.}

La crisis de Irak y su posterior guerra han tensionado las bases del sistema político mundial imperante desde el término de la guerra fría, planteando un importante desafío a la política exterior independiente de Nueva Zelandia, a la vez que ha resaltado las diferencias existentes entre los partidos políticos. El impacto más profun- 
do de dicha política en la política mundial afectó al multilateralismo y a las Naciones Unidas. En el período de tensión anterior a la guerra, el gobierno laborista, fiel a sus creencias, dejó claro que Nueva Zelandia se uniría a Estados Unidos sólo si la acción militar contra Irak era autorizada por las Naciones Unidas. Esta postura, similar a la adoptada por Chile, tiene sus fundamentos en los principios de multilateralismo, el imperio de ley y el respeto a las decisiones del Consejo de Seguridad de las Naciones Unidas. Desde esta perspectiva, las acciones más efectivas son las que se generan a partir de decisiones de una comunidad de naciones, más que de acciones unilaterales, como la adoptada por la coalición liderada por Estados Unidos. Históricamente, Nueva Zelandia ha estado más cerca de la perspectiva europea de relaciones internacionales -que no se alinea a la política conservadora estadounidense- al ser más activa en abordar internacionalmente los problemas de la paz, los derechos humanos, los temas sociales, de la pobreza y el medio ambiente, a la vez que asigna un rol a los organismos multilaterales -particularmente las Naciones Unidas- en el manejo de estos.

A esta visión, se contrapone la que percibe que la lucha contra el terrorismo justifica ataques preventivos y, se aproxima más al neoconservadurismo estadounidense, escéptico respecto de las instituciones multilaterales que limitan el poder de los Estados Unidos y su eficacia. Para este sector, la actual política exterior neozelandesa carece de realismo frente a excesos de tiranos o al tipo de amenazas y conflictos que genera el te- rrorismo, argumentando que ante una situación de naturaleza terrorista, Nueva Zelandia estaría más seguro con el respaldo de los Estados Unidos, preparado para la acción. Es así como, frente al conflicto de Irak, propició el apoyo práctico a Estados Unidos y sus aliados desde antes del conflicto.

\section{Después de su presidencia del APEC, Nueva Zelandia lanzó su "estrategia latinoamericana".}

Si bien la independencia de Nueva Zelandia en materia de relaciones exteriores ha sido compartida por ambos partidos, esta se asocia más a gobiernos laboristas idealistas, a los que se les critica no avanzar lo suficiente respecto de los principales intereses del país, es decir, en materias de seguridad y económicas, y que han potenciado la tradicional preferencia neozelandesa por valores socialdemocráticos y liberales internacionales.

En materia de alianzas las visiones difieren, por cuanto opositores al gobierno de Helen Clark se inclinan por fortalecer las relaciones con dos de los principales aliados, Australia y los Estados Unidos, y critican que con Australia -país al que emigran muchos universitarios neozelandeses al titularse- se han perdido beneficios en materia de residencia y de seguridad social, lo que limita las opciones personales y que con Estados Unidos no se ha logrado aún un acuerdo de libre comercio, que favorecería al país con el acceso al enorme mercado estadounidense. La prioridad dada a Chile o Singapur es 
secundaria respecto de estos. En cuanto al gobierno, como antes se indicó, su política de alianzas apunta a los países asiáticos, especialmente China, América Latina -con prioridad en Chile, APEC, etc., $y$ reconoce en las fuerzas de paz una forma de contribuir a la paz mundial. A un nivel profundo, el laborismo está convencido de que el mundo actual no se compone de imperios y colonias, sino más bien está lleno de oportunidades, lo que hace innecesario adherir a todas las decisiones que pueda adoptar la superpotencia.

Si Nueva Zelandia fuera realmente independiente, quizás dejaría de mirar a Australia, Estados Unidos o Inglaterra como puntos de primera referencia. En la práctica, pesan los estrechos vínculos que mantiene con éstos en áreas importantes como la defensa, la inteligencia y, en parte, las relaciones exteriores, por no mencionar las similitudes culturales existentes. Por otra parte, estigmatizar a los partidos con atributos que comparten o han compartido es algo ficticio, considerando que ambos fueron proteccionistas hasta los años ochenta, han apoyado a las Naciones Unidas desde su creación y ahora están en favor de una revisión de la estructura de su Consejo de Seguridad. Igualmente, ambos han tratado con pragmatismo los temas de seguridad y económicos, que son centrales a los intereses del país.

Chile y Nueva Zelandia: Socios Estratégicos en el Pacífico Sur

Nueva Zelandia, distante 10 mil kilómetros, comparte con Chile el Océano
Pacífico Sur, entre los paralelos $35^{\circ}$ y $45^{\circ}$, esto es, a grandes rasgos entre Santiago y Puerto Aysén. En clima y paisaje es como el Chile de la VIII a la XI regiones. En sus memorias, Pablo Neruda, quien contó con apoyo neozelandés para ser electo en UNESCO en los años setenta, comienza con las palabras: "Bajo los volcanes, junto a los ventisqueros, entre los grandes lagos, el fragante, el silencioso, el enmarañado bosque...". El poeta se refería al sur de Chile, si bien la descripción se ajusta también a Nueva Zelandia, cuya zona central de la Isla Norte se asemeja a la Región de Los Lagos y sus grandes bosques nativos de la Isla del Sur, a nuestros bosques australes. El océano no siempre ha sido una barrera. Los navegantes polinesios de antaño sentaron presencia en la Isla de Pascua y en Nueva Zelandia, generándose un vínculo especial entre ambos países.

\section{La idea de independencia ha estado presente como crítica progresista a un patrón existente.}

No obstante las diferencias culturales entre Chile y Nueva Zelandia existe a la vez una creciente identificación, que se basa en factores y visiones comunes e intereses mutuos. A grandes rasgos, comparten un modelo de desarrollo análogo, un perfil económico similar y de ahí el interés bilateral por conocerse y estrechar lazos. Cabe destacar, entre los factores que presentan en común, que:

- Ambos países comercian a nivel 
mundial y comparten la obligación de incrementar su comercio exterior. Su población es pequeña para sustentar la producción interna y dependen de las exportaciones para crear prosperidad.

- Basan su crecimiento en los recursos naturales, que les proporcionan una ventaja comparativa, y necesariamente deben innovar y procurar avanzar en la escala de valor para mejorar el nivel de vida de sus habitantes.

\section{Las acciones más efectivas son las que se generan a partir de decisiones de una comunidad de naciones.}

- Evolucionaron de sistemas centralizados a economías de mercado, y son reconocidos internacionalmente por sus reformas económicas -ambos manejan tipos de cambio libre y poseen bancos centrales autónomos, abolieron los controles a los movimientos de capital, los subsidios a la industria y los controles de precios $\mathrm{y}$, privatizaron empresas públicas, entre otras medidas, que les han permitido crear economías competitivas, orientadas al exterior y bien clasificadas en las encuestas internacionales por su apertura y transparencia. En 2004 presentan buen desempeño en la medición del Foro Económico Mundial (Growth Competitiveness Index), que analiza el potencial de los países para lograr un crecimiento a mediano y largo plazo en la economía globalizada, a partir del entorno macroeconómico, la calidad de las instituciones públicas, y la tecnología.

- Son países del "Nuevo Mundo", democráticos y abiertos, que se sustentan en visiones y principios similares y que requieren de nuevas ideas e innovación para insertarse con ventajas a nivel internacional y,

- Ambos se proyectan a los asuntos internacionales para influir en el diseño de un mundo que se ajuste mejor a sus necesidades. En organismos e instancias internacionales, tales como la OMC, las Naciones Unidas y el APEC, promueven y defienden sus visiones e intereses comunes respecto de las mejores formas de enfrentar los desafíos que plantea la globalización a pequeños países democráticos de economía abierta.

\section{Atractivo de Nueva Zelandia para Chile}

Nueva Zelandia ha logrado diseñar una estructura económica que, aun sobre la base de materias primas, exhibe un buen nivel de ingresos, con una brecha pequeña en su distribución, ha erradicado la pobreza e integrado las minorías étnicas, en especial a los maoríes. Su administración pública y gobierno son admirados por su austeridad, institucionalidad moderna, alta eficiencia y orientación a metas de rendimiento y en el mercado laboral hay interesantes avances en materia de flexibilización, factores que resultan funcionales a los objetivos del país y su empresa. Nueva Zelandia ha desarrollado una eficiente base industrial y de servicios complementarios, sin embargo, tropieza con dificultades para acelerar su transformación y crear la riqueza requerida para alcanzar el nivel de desarrollo de otros países también anglosajones en su 
origen. Cabe destacar que Nueva Zelandia desarrolla un proyecto-país de ciencia y tecnología para agregar valor a los productos que exporta, promoviendo la creación de nuevas industrias, como la de biotecnología, que presta especial atención a mejorar los productos agrícolas y forestales, puntales económicos, y procura romper su dependencia de los "commodities", favoreciendo la creación de nuevas industrias, en áreas como las de servicios. "El señor de los anillos" es ejemplo de un producto que puede dar inicio a una industria de la comunicación con mayor valor agregado.

A Chile le interesa la ventaja comparativa de contar con un socio de gran confiabilidad en el Asia Pacífico, de superior grado de desarrollo, con capacidad científica de primer nivel aplicable a su industria, de simétrica estructura económica y coincidencia política. Un acuerdo de Asociación Económica Estratégica (AAEE) con esta nación desarrollada ayudará a consolidar su entrada al Asia, continente del que Nueva Zelandia está estratégicamente cercana. Treinta por ciento del comercio de Chile es con Asia, así como un $37 \%$ de las exportaciones de Nueva Zelandia. Esta es una región de fundamental importancia para ambos.

\section{Atractivo de Chile para}

\section{Nueva Zelandia}

El potencial de los vínculos con América Latina es valorado por Nueva Zelandia en el marco de su estrategia global. Chile es un foco principal de esa estrategia, por ser el país latinoamericano con el cual mantiene la más larga tradición de relaciones, comparte principios e intereses económicos, así como enfoques similares respecto de la política y la cooperación internacionales y la interacción en diversos ámbitos -que incluyen los de ECOTECH en APEC, el derecho del mar, la conservación marina, la Antártica y el desarme.

\section{La política de alianzas del gobierno reconoce en las fuerzas de paz una forma de contribuir a la paz mundial.}

Durante los últimos 30 años, Chile ha sido el socio más cercano de Nueva Zelandia en la región latinoamericana, adquiriendo conocimiento mutuo mediante el compartir inversiones, experiencias y know how en rubros en los que se complementan. Al mismo tiempo le ha servido como puerta de enlace hacia la región. Un Acuerdo de Asociación Económica Estratégica que involucre a Chile proveería a Nueva Zelanda de un eslabón estratégico en una de las economías más desarrolladas latinoamericanas. Esto aportaría una plataforma para la cooperación del sector privado incluyendo la inversión y la transferencia de tecnologías y oportunidades adicionales para vínculos estratégicos en terceros mercados. Chile es actor proactivo del libre comercio a nivel mundial, puesto que posee acuerdos de libre comercio con Estados Unidos, la Unión Europea, y Corea del Sur, entre otros. En la región latinoamericana, su red de acuerdos facilita el acceso a los mercados de la región de las exportaciones 
de Nueva Zelandia y contribuye a asegurar su comercio de bienes y servicios y sus intereses económicos. Carecer de estas credenciales, que se ven como ventaja significativa, puede reducir las oportunidades de operar con éstos.

Muchos de estos son elementos diferenciadores respecto de otros países latinoamericanos, que inclinan la balanza en favor de Chile al iniciar Nueva Zelanda una asociación estratégica que le abra paso en América Latina.

\section{Colaboración y asociación para com-} petir en los mercados internacionales

Una pregunta relevante para dos economías de similar estructura y base productiva es: ¿Qué expectativas pueden existir para sus relaciones económicas $y$ comerciales? Ninguno de los dos países tiene el potencial para llegar a ser el mayor mercado del otro, debido a su tamaño y a la similitud de su producción. Dado el bajo nivel de protección de ambos, las ventajas que generará en el comercio de bienes el retiro del arancel básico serán poco significativas. Estimaciones neozelandesas basadas en flujos comerciales recientes, determinaron que el ahorro de sus exportadores, por este concepto, ascenderá a 4 millones de dólares al año. Otro efecto de la baja protección arancelaria es que un acuerdo de asociación económica estratégica no implicará ajustes significativos a los sectores protegidos de las economías.

El intercambio mutuo presenta aún un bajo perfil en sus mercados. El mayor conocimiento y el incremento de los vín- culos, la complementariedad de ambas economías y la voluntad de asociación hacen que exista potencial para el crecimiento del comercio de bienes y servicios, y también de los flujos productivos de inversión en ambos sentidos, lo que determina la relación a largo plazo. La tendencia reciente refuerza lo indicado, en tanto el comercio crece e incorpora gradualmente la comercialización de nuevas tecnologías, la mayor diversidad de los bienes industriales y servicios, y hace recíprocamente útiles sus mercados.

\section{Pese a las diferencias culturales, Chile y Nueva Zelandia tienen visiones comunes e intereses mutuos.}

Un tema relevante es la condición de competidores de Chile y Nueva Zelandia en productos y mercados. En efecto, ambos son exportadores significativos de materias primas, con intereses similares que les han llevado a competir en algunos mercados. Sin embargo, todavía hay mucha complementariedad entre ambas economías, en las que subsisten algunas áreas sensibles en el comercio. La paradoja es que al tener una producción similar y ser competitivos, existe mucho para beneficiarse mediante la cooperación e intercambio de experiencias. Ya esto ha venido ocurriendo en las últimas décadas, en que la relación económica se ha caracterizado por importantes inversiones de empresas neozelandesas en sus equivalentes de los sectores forestal y de alimentos, específicamente en las industrias maderera y de productos lácteos. Desde los 
años ochenta estas visualizan el beneficio estratégico de colaborar invirtiendo en producción chilena, perfilando a Chile como socio natural, el segundo después de Australia.

\section{A Chile le interesa la ventaja comparativa de tener un socio de gran confiabilidad en Asia Pacífico.}

Actualmente hay importantes espacios e interés de colaborar e innovar para que juntos ambos países puedan llegar más lejos. Las semejanzas adquieren importancia especial desde el punto de vista de la innovación tecnológica, que permite compartir tecnologías productivas en industrias primarias y generar nuevas asociaciones, incluyendo empresas conjuntas. Ofrece también la posibilidad de colaborar en investigación, intercambio de personal, información e ideas, experiencias en tendencias industriales $y$, frente a los desafíos que presenta el acceso y la comercialización en terceros mercados de sus ventajas comparativas en kiwi, salmones, vino y pino radiata. En este último rubro suman la mitad de las plantaciones mundiales, lo que les da ventajas para dotar de material de construcción a China. Por el momento, se visualiza realizar "joint ventures" e inversiones conjuntas que permitan acceder, en América Latina y Asia Pacífico a los mercados que se abren con la globalización. Nueva Zelandia está a la vuelta de Asia para Chile y Chile facilita el acceso a Sudamérica.

A nivel específico, conocido es el desarrollo por Nueva Zelandia del "Kiwi Gold", de color amarillo y que no tiene la acidez del tradicional kiwi de color verde. Aquí hay valor agregado, patentamiento de procesos y mejores precios en los mercados internacionales para exportadores, a quienes no les interesa vender la planta y con ello su ventaja a otros países. Una asociación con Nueva Zelandia, que genere inversión en producción en Chile, puede incorporarle a este proceso. Por otra parte, hay desafíos sectoriales comunes tales como en el sector forestal, donde los exportadores de pino radiata, enfrentan la certificación ambiental, aranceles escalonados sobre productos de madera de valor agregado, y deben asegurarse que los acuerdos ambientales internacionales no discriminen contra países con extensas plantaciones forestales. Una mayor y más amplia cooperación se abre en áreas de la agricultura, que incluyen a algunos ámbitos sensibles para Chile como el sector lácteo, donde los agricultores neozelandeses con el término de los subsidios, reemplazaron los aportes fiscales con aumentos de la producción, alcanzando resultados más favorables que los de Chile en el rubro. Esto ha generado espacio para conflicto, pero también oportunidades para la cooperación comercial y tecnológica, y el desarrollo, si ambos países se coordinan para invertir, aportar sus capacidades y abrir mercados a sus productos de exportación. Hay también espacios para la cooperación en la pesca, entre otros. Nueva Zelandia sólo protege las industrias textiles, de la ropa y de calzado y Chile no es exportador significativo de estos productos. 
El mayor crecimiento se dará producto de la integración natural de ambas economías. Ejemplos de esto se observan en los resultados del Acuerdo de Libre Comercio de Chile con Canadá. Una evaluación oficial canadiense al cumplir tres años de vigencia arrojó que el comercio bilateral había aumentado en $33 \%$, mientras las inversiones canadienses en Chile un 57\%. En materia de exportaciones, destaca la diversificación y el carácter no tradicional de las canadienses, así como el crecimiento de los envíos chilenos a Canadá, a un ritmo que convertía a éste en el segundo mercado de más rápido crecimiento para Chile. Por su parte, el Acuerdo CER de Nueva Zelandia con Australia ha potenciado su complementariedad, generando un perceptible incremento del comercio intra-industrias. Un acuerdo de asociación económica estratégica facilitará a las compañías vender sus bienes y servicios o invertir en ambos mercados, centrándose en los sectores en que tienen expertise nacionalmente. Desde que el CER entró en acción en 1983, el comercio bilateral de bienes entre Nueva Zelandia y Australia se quintuplicó, alcanzando una cifra aproximadamente $39 \%$ superior al crecimiento de estos a nivel global para Nueva Zelandia. Una asociación económica estratégica entre Chile y Nueva Zelandia puede también conducir a un creciente comercio intra-industrias.

En los servicios, la expansión se dará igualmente en áreas con ventajas en ambas economías. Dada su complementariedad, las áreas con mayor potencialidad de crecimiento se encuentran, aunque no exclusivamente, en los servicios relacio- nados con la agricultura, la silvicultura, la ingeniería, la energía, y la consultoría. La educación y el turismo son también dos sectores que ofrecen excelente potencial de crecimiento. Estos apuntarán a los mercados propios y regionales de cada uno.

\section{Un acuerdo de asociación económica estratégica con Chile aportaría una plataforma para la cooperación del sector privado.}

Con intereses comunes en sectores primarios, una asociación permitiría a Chile y Nueva Zelandia trabajar más unidos a nivel empresarial -generando empleos e ingresos de exportación- y a sus gobiernos potenciar el apoyo dado para procurar liberalizar la agricultura y otras industrias de recursos naturales, que continúan siendo las áreas más distorsionadas del comercio internacional. Dentro del Grupo Cairns de naciones agrícolas exportadoras, Chile y Nueva Zelandia han trabajado juntos por mucho tiempo para liberalizar el comercio agrícola mundial y para poner fin a los subsidios que distorsionan los mercados mundiales. Dado que los productos del campo, huertos, forestales y del mar suman más de $60 \%$ de las exportaciones de Nueva Zelandia y una proporción significativa de las chilenas, en ambos países son prioridades nacionales de primer orden.

Un acuerdo entre Chile y Nueva Zelandia será una progresión natural de la relación bilateral y servirá de marco para 
incorporar y dar nuevo énfasis a previos acuerdos políticos, económicos, comerciales, educacionales y tecnológicos ya alcanzados.

\section{Potenciación del factor humano y de los contactos}

La educación es un elemento crucial del desarrollo neozelandés y un área para aprender de estos y aplicar mejoras en Chile. En Nueva Zelandia, país que abordaremos en particular, la educación ocupa sectorialmente el quinto lugar en la economía y ha desarrollado una revolución que reemplazó una estructura centralizada por otra que da mayor responsabilidad a escuelas, institutos y universidades, proporcionando el gobierno vigilancia, orientación y recursos a los centros de estudio. Aquí hay algunas consideraciones importantes que efectuar:

- Nueva Zelandia es hoy un país étnicamente más heterogéneo. Los maoríes, originarios de Polinesia, constituyen un séptimo de la población y el viraje de los ochenta hacia el sudeste asiático atrajo una importante inmigración de la región, aumentando su diversidad cultural. Datos oficiales indican que en 2003 vivían en ese país 346 mil asiáticos y, que estos superarán los 600 mil (13\% de la población) hacia el año 2021.

- El país enfrenta dificultades para retener a algunos de sus propios universitarios, quienes una vez titulados van a trabajar a Australia o Gran Bretaña.

- A nivel de industria, compite actualmente con Australia y Canadá en la enseñanza del inglés internacional. En
2003, 282 mil alumnos extranjeros lo estudiaban, especialmente asiáticos $-40 \%$ o más- y los ingresos por este concepto se elevan a 1.700 millones de dólares.

- En un mundo más globalizado, Nueva Zelandia necesita potenciar sus vínculos con Sudamérica y atraer a occidentales, para diversificar la demanda por educación y fortalecer sus vínculos económicos y comerciales.

Para aumentar el conocimiento mutuo y romper con la percepción de lejanía, se requiere crear contactos personalizados. Con este propósito, en el acuerdo con Nueva Zelandia, Chile intenta lograr un arancel local para acceso a las universidades neozelandesas. Desde ya se ha percibido interés en ambos países por crear vínculos en las áreas de ciencia y tecnología, artes, cultura, académica y educativa. Las universidades neozelandesas tienen a su vez enlaces de intercambio académico y de investigación comunes, y el gobierno de Nueva Zelandia ofrece becas que permiten que estudiantes chilenos sigan cursos de posgrado en Nueva Zelandia. Proyecciones existentes estiman que hacia 2010 habrá más de tres mil estudiantes chilenos de posgrado en universidades neozelandesas y con seguridad, entre ellos habrá profesores y alumnos perfeccionando su inglés, de acuerdo con la política bilingüe de Chile y la realidad de que, conforme una medición de la Universidad de Chile, el 65\% de los habitantes de Santiago carece de conocimientos de ese idioma. Otros en Auckland, Wellington y Christchurch continuarán construyendo capacidades y competencias en áreas en las cuales ambos países 
comparten fortalezas como en los campos de la agricultura, las ciencias forestales, la silvicultura, las ciencias del mar y la geofísica. Cálculos de la Cancillería chilena indican que de aquí a 2010 una veintena de estos programas contribuirá a innovar y acrecentar los vínculos entre ambos países.

Por otra parte, el español es el idioma extranjero de mayor crecimiento que se enseña en los colegios y universidades de Nueva Zelandia. El idioma es la clave para apreciar la cultura de otros, y a medida que aumente su seguridad con el idioma un mayor número de neozelandeses visitará Chile y el resto de América Latina.

\section{Acuerdo de Asociación Económica Pacífico Tres: Singapur, Nueva Zelandia y Chile}

Los vínculos con estos países presentan larga data y creciente valorización, acorde con la prioridad dada por Chile a la región del Pacífico en las últimas décadas. En 1988 y 1989, fecha en que materializó un proyecto internacional visionario y pionero, tripartito público, privado y académico, denominado "Chile en la Cuenca del Pacífico: Experiencias y Perspectivas Comerciales en Asia y Oceanía”, que me correspondió liderar, Singapur tenía un ingreso per cápita de 7 mil dólares. El comercio con Chile alcanzaba a 15 millones de dólares y se establecían recién los primeros vínculos comerciales organizados, al crearse la Cámara binacional de comercio. Nuestra percepción en aquel entonces era que Singapur concebía al Pacífico como una comunidad que incorporaba al Asia y en la vertiente oriental del Pacífico sólo a Estados Unidos y Canadá, presentando el Pacífico Sur menor interés para aquel país. En esa fecha, los principales indicadores económicos de Nueva Zelandia eran bastante inferiores a los actuales, el intercambio con Chile era de 20 millones de dólares y la inversión neozelandesa en Chile alcanzaba los 500 millones de dólares, ubicando a ese país en el tercer lugar de inversores del Pacífico en Chile, a continuación de Estados Unidos y Australia. A esa fecha la meta era generar inversiones chilenas en empresas neozelandesas. Quince años se ha debido esperar para que, en un entorno de globalización, Chile, Nueva Zelandia y Singapur, gozando en común de una buena evaluación internacional por sus desempeños económicos, institucionales y de gobernabilidad, materialicen ese remoto anhelo de formar asociaciones para fortalecer en conjunto su posición competitiva en los mercados globales y de la región.

\section{Una asociación económica estratégica no implicará ajustes significativos a los sectores protegidos de las economías.}

En cuanto a su perfil económico actual, Singapur tiene hoy 4,2 millones de habitantes, un ingreso per cápita de 22 mil dólares, un PGB de 94 mil millones de dólares y un intercambio comercial global de 
280 mil millones, incluidos los servicios, que representan alrededor de un $70 \%$ y de $30 \%$ de participación en el producto, respectivamente. En materia de servicios, esta ciudad-Estado es un importante centro de transporte, distribución y finanzas en Asia, siendo sus sectores portuarios, aéreos y financiero sus ejes principales, en conjunto con el turismo, que con 7 millones de visitantes anuales es también relevante para la economía. La industria, a su vez, principalmente de exportación, presenta una especialización en rubros como la electrónica y las telecomunicaciones y en su afán diversificador, hoy incentiva especialmente el desarrollo de los sectores farmacéuti$\cos$ y de biociencias, con especial foco en el mercado de China. Con Chile el intercambio se mantiene bajo, no superando los 60 millones de dólares.

Nueva Zelandia, a su vez, tiene $4 \mathrm{mi}-$ llones de habitantes, su ingreso per cápita es de 17 mil dólares, el PGB es de 60 mil millones de dólares y el intercambio comercial global alcanza a 34 mil millones. Su economía depende fuertemente del comercio exterior, constituyendo las exportaciones de bienes y servicios el 33\% del producto. Chile con un total de $40 \mathrm{mi}$ llones de dólares representa menos del 0,3 por ciento de ese intercambio.

Ambos países han alcanzado estándares de países desarrollados, son altamente competitivos, eficientes en materia de

Principales indicadores económicos de Singapur

\begin{tabular}{|l|c|c|c|}
\hline & 2001 & 2002 & 2003 \\
\hline PGB (US\$bill. Precios 1995) & 88,073 & 90,748 & 94,286 \\
Variación PGB & $-1,9 \%$ & $2,2 \%$ & $1,1 \%$ \\
Producto per Cápita (US\$) & 20.816 & 21.162 & 21.825 \\
IPC & $1 \%$ & $-0,4 \%$ & $0,5 \%$ \\
Tasa de Desempleo & $3,3 \%$ & $4,4 \%$ & $4,7 \%$ \\
Importaciones (US\$bill.) & 115,919 & 116,336 & 131,334 \\
Exportaciones (US\$bill.) & 121,686 & 125,042 & 144,126 \\
Reservas Internacionales (US\$bill.) & 75,800 & 82,276 & 96,324 \\
Balanza de Pagos (US\$bill.) & $-0,894$ & 1,277 & 6,759 \\
\hline
\end{tabular}

Fuente: Ministerio de Comercio e Industria de Singapur

Principales indicadores económicos de Nueva Zelandia

\begin{tabular}{|l|c|c|c|}
\hline & 2001 & 2002 & 2003 \\
\hline PGB (USSbill. Precios 1995) & 55,802 & 58,6 & 60,592 \\
Variación PGB & $\mathrm{n} / \mathrm{d}$ & $5 \%$ & $3,4 \%$ \\
Producto per Cápita (US\$) & 13.950 & 14.900 & 16.930 \\
IPC & $3,2 \%$ & $2,8 \%$ & $1,5 \%$ \\
Tasa de Desempleo & $5,3 \%$ & $5,1 \%$ & $4,6 \%$ \\
Importaciones (US\$bill.) & 15,644 & 15,269 & 17,688 \\
Exportaciones (USSbill.) & 15,68 & 15,519 & 16,102 \\
Reservas Internacionales (US\$bill.) & 8,566 & 7,723 & 9,115 \\
Balanza de Pagos (USSbill.) & 9,908 & 7,066 & 0,6 \\
\hline
\end{tabular}

Fuente: Tesoro (Treasury) de Nueva Zelandia 
costos de transacción y transparentes.

En enero de 2001 entró en vigencia un Acuerdo de Asociación Económica (AAEE) entre Nueva Zelandia y Singapur, que contiene una cláusula que permite su expansión a otros países. En virtud de esa cláusula, Chile se incorporará a este acuerdo, a comienzos de 2005, cuyo resultante se conoce como Pacífico Tres. Este acuerdo será amplio, en cuanto abarcar una proporción significativa del comercio y no excluir sectores, comprehensivo al incluir todos los temas relacionados al comercio, con visión de futuro y, mantendrá el enfoque de los restantes acuerdos comerciales bilaterales y regionales, de sus miembros, en cuanto a centrarse en crear comercio, en lugar de desviarlo, de incrementar los flujos de inversión mutuos y la transferencia tecnológica.

\section{Pese a tener una producción similar} la cooperación y el intercambio de experiencias pueden beneficiar a ambos países.

En este análisis se ha observado que los beneficios en la relación comercial directa de estas tres economías son de alcance limitado, tanto por lo pequeño de sus mercados internos, como por su alto grado de apertura actual y, en el caso de Nueva Zelandia, porque Chile exporta casi los mismos productos en idénticas temporadas. En la búsqueda de claves, es muy decidor que los tres países negocien simultáneamente acuerdos con países del Pacífico y especialmente con China. Es precisamente allí donde está la relevancia de este Acuerdo, en cuanto contribuya a aumentar las exportaciones a terceros mercados, por medio de operaciones conjuntas de inversión, tecnología y distribución, y los miembros se preparen para innovar en sus negocios y enfrentar en conjunto los mercados y los nuevos desafíos de la globalización. Como participantes de un AAEE trilateral, Chile, Nueva Zelanda y Singapur estarán en una excelente situación para explorar y desarrollar oportunidades en terceros mercados del Pacífico, tales como China, Japón, Corea y Vietnam.

Desde esta perspectiva, un Acuerdo Pacífico Tres tiene ventajas económicas y estratégicas para sus socios. Para Nueva Zelandia y Chile, una asociación que incremente los flujos de comercio implicará entre otros beneficios una reducción en los costos de fletes y por ende mayor competitividad y, la participación de Singapur contribuye al desarrollo y consolidación de sus relaciones comerciales y económicas con la región de Asia Pacífico, transformándolos en socios estratégicos más atractivos. Desde la perspectiva chilena y de sus empresas, Nueva Zelandia le proporcionaría un acercamiento al cada vez más competitivo mercado regional, y un P3, que incluya a Singapur completaría el triángulo, en su búsqueda por generar asociaciones eficaces para integrarse y aventajarse en los mercados asiáticos. A su vez, esta ciudad-Estado, referente como plataforma de negocios y centro logístico en Asia, puede aportar a Chile inversiones y know how en sectores de servicios relacionados a sus fortalezas, 
para mejorar la competitividad e incrementar la conectividad chilena con sus vecinos, apoyando la aspiración de transformar al país en un centro de distribución en América Latina para los productos provenientes de Asia y de salida para productos del cono sur latinoamericano al Asia. Desde la perspectiva de Nueva Zelandia y Singapur, la asociación con Chile les permitiría proyectarse a terceros mercados, como se indicó, y a las empresas neozelandesas y singapurenses emplear a Chile como plataforma hacia América Latina, aprovechando su infraestructura comercial y de acuerdos de libre comercio.

\section{El mayor crecimiento será producto de la integración natural de ambas economías.}

De contribuir efectivamente el Acuerdo Pacífico Tres a estos objetivos, será un gran logro para Chile, por cuanto hoy por razones de escala, integración incipiente en las estrategias y procesos de negocios, así como en la conectividad a nivel subregional, entre otras, el país no logra aún densificar las relaciones con países como Argentina, Brasil y otros vecinos, para transformarse en la plataforma de negocios que aspira ser. A nivel de resultados esperados, la evidencia empírica del Acuerdo de Asociación Económica de Nueva Zelanda con Singapur, es que la inversión y el comercio entre estos países aumentó, incluso antes de formalizarse.

El Acuerdo Pacífico 3 es compatible con la naturaleza abierta de la política co- mercial y económica de Singapur, país cuyo vigor y crecimiento se sustentan en una economía abierta. La ausencia de aranceles de importación y de barreras no arancelarias combinadas con el AAEE bilateral en ejecución con Nueva Zelandia -que aporta un marco de referencia útil-asegurará una transición relativamente suave a un "P3", aun cuando haya diferencias importantes entre las economías y Singapur todavía proteja su sector de servicios. Si bien un AAEE proporcionará a Chile y Nueva Zelandia la base para promover un sentido de asociación, que se manifieste en crear empresas conjuntas, colaborar en otros mercados, compartir tecnologías y facilitar nueva inversión en ambas direcciones, la dimensión P3 podría generar inversión adicional de Singapur. Asimismo, aumentar el movimiento de personas con competencias, capital, ideas y conocimiento. El aumento de la conexión global es un factor fundamental para el crecimiento y la innovación, bases requeridas para mantener y potenciar economías vigorosas y capaces de producir altos ingresos sostenibles. Mejoras en las exportaciones y las inversiones, mediante un AAEE tripartito apoyarían este objetivo.

A nivel técnico, el acuerdo P3 será amplio y fijará patrones de calidad en las reglas comerciales que ayuden a promover la liberalización comercial y de inversiones, entre sus miembros y en la región de APEC. Basándonos en el AAEE de Nueva Zelandia y Singapur puede deducirse que dicho pacto, entre otros beneficios, establecerá una desgravación arancelaria inmediata para el intercambio de 
bienes, eliminará todo subsidio a las exportaciones e impedirá el uso de salvaguardias o restricciones no arancelarias (excepto en situaciones objetivas de crisis de balanza de pagos), liberalizará el mercado de servicios (cuyo potencial fue señalado respecto del ámbito chileno-neozelandés) y establecerá un mercado común de proveedores del sector público. Se proyecta asimismo que incorpore un concepto global en materia de inversiones y que genere beneficios en áreas como la transferencia científica y tecnológica, la innovación productiva y estándares laborales y ambientales. La educación y la consultoría en áreas con ventajas se potenciarán, pudiendo generarse beneficios mediante interacción en otros temas como políticas públicas, gestión de gobierno y transparencia, desarrollo de la salud y la previsión. Otros temas que se incluirán son el e-comercio, la política de competencia, la cooperación aduanera, la propiedad intelectual, excepciones y mecanismos de solución de controversias.

\section{Para romper con la percepción de lejanía hay que crear contactos personalizados.}

Cabe señalar, que en el ámbito de la cooperación, que es transversal al Acuerdo, en las negociaciones se ha avanzado, al acordarse un esquema de objetivos, áreas y mecanismos que aseguren la identificación de oportunidades y la operación efectiva de lo que se pacte, con participación de los gobiernos, sectores privados y universidades.
Una Asociación Económica Estratégica P3, basada en el mutuo interés de Chile, Nueva Zelandia y Singapur, fortalecerá en términos económicos sus vínculos políticos y culturales, y será una muestra concreta del compromiso de estos países con la región, abriendo posibilidades para negociar como grupo acuerdos comerciales con otros países integrantes del APEC. Desde una perspectiva regional y global, un AAEE de estos tres países, miembros activos y motivados del APEC, podría contribuir mediante un efecto de demostración importante a avanzar hacia las metas de Bogor del APEC.

Como se aprecia, estos socios del Pacífico y del Nuevo Mundo tienen muchas causas en común que hacer avanzar en este milenio, en beneficio del desarrollo y el bienestar de sus poblaciones.

\section{BIBLIOGRAFÍA}

Cameron, Nadia. "The World According to Lee Kwan Yew", Business Asia, 11 de enero de 2000.

"Remarks by Singapore Prime Minister Goh Chok Tong in the Singnig Ceremony for the USA Singapore Free Trade Agreement", EE.UU., 2003.

Jian Yang. "New Zealand's Foreign Policy: Independence, Realism and Idealism: Reports on a Discussion on Issues Relating to New Zealand's Stance in the World", New Zealand International Review, 7 de enero de 2003.

Clark, Helen. "Towards a More Pro-Active Role", International Relations / New Zealand Foreign Policy. New Zealand International Review, 7 de enero 1998.

"Chile y Nueva Zelandia: Socios en el Nuevo Mundo", Phil Goff, Ministro de Relaciones Exteriores, Comercio y Justicia de Nueva Zelandia, en Sociedad de Fomento Fabril, Santiago, Chile, 27 de marzo de 2001. 
O’Meagher, Matthew. "New Zealand and Chile: A Thwarted Friendship", New Zealand International Review, 3 de enero de 2000.

"Chile y Nueva Zelandia: Luna de miel en el Pacífico Sur-Matrimonio por conveniencia" y "Nueva Zelandia: Las características de un país con el modelo chileno", El Mercurio, 28 de marzo de 2004 y 6 de julio de 2002.

"Pacific Three Negotiations: Chile, New Zealand and Singapore", The New Zealand Ministry of Foreign Affairs \& Trade-Latin America. 20032004.

"Chile, New Zealand and Singapore Closer Economic Partnership", The New Zealand Ministry of Foreign Affairs \& Trade-Latin America. 2003-2004.

Sitio Web de la Dirección General de Relaciones Económicas Internacionales del Ministerio de Relaciones Exteriores de Chile, www.direcon.cl:
Negociaciones en Curso -Nueva Zelandia, Singapur y Chile (P3), noviembre de 2004.

Valdivieso Eguiguren, Sergio; Gálvez Carvallo, Eduardo. Chile en la Cuenca del Pacífico: experiencias y perspectivas comerciales en Asia y Oceanía, Santiago, Editorial Andrés Bello, 1989; y UNDP - United Nations, 1990.

Valdivieso Eguiguren, Sergio. "La cooperación económica y técnica y su aporte a la viabilidad del APEC", Revista Estudios Internacionales, $\mathrm{N}^{\circ}$ 144, especial APEC 2004, Santiago, Instituto de Estudios Internacionales de la Universidad de Chile.

Valdivieso Eguiguren, Sergio. "ECOTECH y los APEC Study Centers". APEC Chile 2004, Postítulo a Distancia para Diplomáticos Chilenos, Academia Diplomática Ministerio de Relaciones Exteriores y Universidad Arturo Prat. 